\title{
Online Survey Research: Can Response Factors Be Improved?
}

\author{
Beverly Wright \\ Paul H. Schwager
}

\begin{abstract}
The use of the Internet and online methods for data collection brings about new challenges for academic and managerial researchers. Our objective is to advance our level of knowledge regarding online data collection through an experiment. Using a local organization's e-mail list, we evaluate survey introductory elements such as 10 invitation from a known leader and introductory length. We evaluate resulting levels of response rate, response quality, and respondent satisfaction to assess the effects of modified survey introductory designs. Findings reveal that an invitation from a known leader leads to improved levels of response quality while shorter introductions result 15 in a quicker response from survey participants.
\end{abstract}

KEYWORDS. Data collection, introductory elements, online-surveys, response quality, response rate

The importance of the Internet and other online means for collecting data is perceived as a critical technological advancement in the data 20 collection field. Dillman (2000) describes the use of e-mail, Internet, and other electronic survey methods as a dramatic improvement in

Address correspondence to Beverly Wright, Assistant Professor of Marketing, College of Business, East Carolina University, Greenville, NC 27858. E-mail: wrightb@ecu.edu

Journal of Internet Commerce, Vol. 7(2) 2008

Available online at http://jicom.haworthpress.com

(C) 2008 by The Haworth Press. All rights reserved. 
data collection efficiency. He stresses the importance of the efficiencies gained through electronic data collection as follows:

These efficiencies include the nearly complete elimination of 25 paper, postage, mailout, and data entry costs. Some of these electronic survey methods also provide a potential for overcoming international boundaries as significant barriers to conducting surveys. In addition, the time required for survey implementation can be reduced from weeks to days, or even 30 hours. Most importantly, the introduction of electronic survey methodologies offers the potential for dramatically reducing the close correspondents between sample size and survey costs. (Dillman, 2000, p. 352)

Online methods for data collection are used in a variety of situa- 35 tions including research among the managerial community as well as the academic community. Online surveying is widespread for surveying among individual consumers (e.g., Zviran, Glezer, \& Avni, 2006), business-to-business customers (Grant, Teller, \& Teller, 2005), and industrial markets (McNaughton, 1999). Furthermore, 40 online surveying is being implemented among many different marketing subdiscipline areas including services marketing (e.g., O'Cass \& Fenech, 2003), retail marketing (Seiders et al., 2005), as well as other marketing areas.

Since survey research relies on data collection methods to gather 45 pertinent information, it is critical that researchers develop a deeper understanding of data collection methods and the design factors that impact survey results. Furthermore, given the potential advantages of online data collection, the growing use of online data collection among many areas in business, and the reality of declining levels of 50 participation within managerial and academic surveys (Baruch, 1999; Cycyota \& Harrison, 2006), research involving evaluation of online data collection is warranted.

Previously, Roster et al. (2007) identified low-response rates and item omission rates as issues associated with online data collection 55 methods. This study's focus is to examine the factors that impact data quality and survey participation when online data collection is conducQ1 ted. Social exchange theory (Thibaut \& Kelly, 1959) is used to further explain response quality and participation variations under experimental conditions when using online data collection for research. 


\section{LITERATURE REVIEW}

In addressing the literature we first examine the issues associated with mail and online collection methods and then the use of introductory elements. After reviewing these areas, the literature that provides a framework for the current study is addressed.

\section{Mail and Online Data Collection}

Several academic research studies comparing mail and online methods of data collection have shown that online means for collectQ2 ing data are superior in several ways. For example, Ilieva, Baron, \& Healy (2002) conducted research using both postal and online meth- 70 ods for data collection. Results from their study suggest that online methods are superior in several areas including lower financial resources required, shorter response times, researcher control of sample, reduced survey involvement by the researcher, and efficiency in data entry (Ilieva et al., 2002). Additionally, Cobanoglu, Warde, \& 75 Moreo (2001) find that response rates for e-mail surveys are significantly higher than those of both fax and mail surveys. Wright, Aquilino, \& Supple (1998) tested for differences in response characteristics between adolescents completing paper and pencil questionnaires with sensitive questions versus adolescents completing the same questions 80 using laptop computers. Findings from their research reveal that adolescents were more likely to provide responses to sensitive questions and adolescents reported lower levels of mistrust when online data collection methods were used (Wright et al., 1998).

Despite the positive results of some previous research, additional 85 research surrounding the use of online data collection has not been as positive. For example, Roster et al. (2007) found that the use of online means for data collection produced an inferior response rate, and more item omissions when compared to traditional collection methods. In addition, Roster, Rogers, \& Albaum (2004) observed 90 more neutral evaluations when compared to the use of telephone interviews. Furthermore, Roy \& Berger (2005) conducted a study among managers across several countries and compared response rates between surveys conducted via postal mail and e-mail. These authors found that the mail method for data collection produce 95 higher response rates when compared to the e-mail method (Roy \& Berger, 2005). Additionally, according to Birnholtz et al. (2004), 
the majority of the advantages of online survey research appear to benefit the researcher to a disproportionate level compared to the benefits to respondents. Birnholtz et al. (2004) suggested that there 100 are many instances where respondents are overburdened by the use of online data collection while researchers reap the benefits.

Other research has shown approximately equivalent results between online-based data collection methods compared to other methods. For example, McConkey, Stevens, \& Loudon's (2003) 105 research among accounting professors revealed that online data collection proved to yield similar response rates as well as response content when compared to a mail format. Griffis, Goldsby, \& Cooper (2003) conducted research in a logistics context and found that there were no concerning differences between data collection via online 110 means and paper and pencil methods.

In light of the advantages and despite the disadvantages, the number of online-based surveys conducted among the academic and business communities appears to show a pattern of growth. Furthermore, the online capabilities and equipment available for consumers continues to rise (Dillman, 2000). This increase of technology in households provides more communication possibilities between business researchers and consumers. This online path encourages growth of electronic data collection methods even further.

\section{Introductory Elements}

Survey introductory elements have been under examination for decades. Singer \& Frankel (1982) evaluated differences in response quality and response rate when survey introduction information varied. Their experiment varied survey introductory information regarding the purpose of the survey and survey task expectations. They found no differences in response quality or response rate when these factors were modified among telephone interview respondents. However, these authors emphasize that there were more occasions of item nonresponse for sensitive questions under the conditions of detailed research purposes and even though these differences were not significant, the authors encourage further examinations to confirm this finding (Singer \& Frankel, 1982). In a more recent study, Andersen $\&$ Blackburn (2004) show that the use of intense language in survey introductions produces significantly higher response rates. Furthermore, a study conducted among individuals with a disease revealed 
that survey introductions that detail the study's purpose can result in artificially inflated responses concerning their medical condition (Smith et al., 2006).

\section{Current Study}

This research focuses on the use of online methods for data collec- 140 tion and the changes in response factors when survey introductory elements are varied. Response rate (McConkey et al., 2003), response quality (Hanna et al., 2005), and respondent satisfaction (Manfreda, Batagelj, \& Vehovar, 2002) are evaluated under conditions of varying survey introductory elements (Brennan, Benson, \& Kearns, 2005) to 145 determine the impact of these elements and to provide insight into the most effective means for survey introduction when conducting online-based surveys.

\section{MEASURES}

In the evaluation of any research method is it important that appro- 150 priate measures are established. We address the areas of response rate, response quality, respondent satisfaction, and introductory elements to insure that the proposed measures are established.

\section{Response Rate}

One of the most important measures to consider when evaluating 155 research effectiveness is the level of survey participation or response rate (e.g., McConkey et al., 2003). In their examination of research involving response rates, Shaw, Bednall, \& Hall (2002) found a lack of consistency for response rate despite the criticality of sampling as a building block for most social research. They also discuss the compu- 160 tational similarities and differences between the use of survey participation rate (Tse, 1998) and response rate (Shaw et al., 2002). Kent \& Brandal (2003) argue that response rate is a complex measure, particularly in the context of e-mail survey research. This research utilizes the computation for response rate for use in e-mail survey research as 165 presented in Kent \& Brandal (2003) as follows:

completed questionnaires returned via e-mail

$\overline{\text { (total e-mails sent - e-mail messages returned undeliverable) }}$. 


\section{Response Quality}

Response quality has been used to evaluate effectiveness across 170 multiple methods of data collection efforts for many years (e.g., Singer, 1978). Bush (1984) provides an excellent review of the literature and a broad perspective of the response quality construct. Approximately two decades later, Hanna et al. (2005) provide another meta-analytic view of the various definitions of response quality. Merging these two meta-analyses of response quality, this research utilizes the following measures to represent response quality: 1) item omissions, 2) completeness of answers, 3) response time, and 4) response speed. In addition, the issue of respondent satisfaction can also address the issue of effectiveness.

\section{Item Omissions}

Item omissions, omission rate, or item nonresponse refers to respondents' refusal to answer specific individual questions from a survey task (Bush \& Hair, 1985). This study uses the number of unanswered questions as the measure of item omissions. Questions where a 185 "not applicable" response was possible, such as demographics including age of children in the household for a respondent with no children, were excluded from the computation of item omissions.

\section{Completeness of Answer}

Completeness of answer refers to a respondent providing in-depth, 190 full, complete answers to survey questions (Bush \& Hair, 1985). This has been measured by counting the number of words or characters for a response to one or more open-ended questions (McDaniel \& Rao, 1980). Similarly, this study computes completeness of answer by counting the number of words in response to the most important and applicable open-ended question from a brief survey to represent levels of completeness of answer.

\section{Response Time}

Response time is the amount of time it takes for the respondent to complete one survey response (Weible \& Wallace, 1998). This 200 involves recording survey task start times and end times on a perrespondent basis. While we did have a method for capturing response 
time using online monitoring, we decided to use self-reported response time for the following reasons. First, respondents returned questionnaires in a variety of ways. While most were completed using a desig- 205 nated Web site, others were returned via e-mail, mail, and fax. Since online methods of collecting data were not available for these response avenues, we relied on self-reported response times. Furthermore, our monitoring method from our Web site application begins the moment the respondent opens the survey form. The monitoring system does 210 not take into account situations where respondents might open the survey form yet delay the start of their response due to extraneous factors. For these reasons, we chose to use self-reported response times.

\section{Response Speed}

Response speed is a measure in days of the time it takes for a respon- 215 dent to return a completed survey response to the appropriate party (Cobanoglu et al., 2001). We delivered an invitation to participate via e-mail on Tuesday afternoon, September 12, 2006. Since we were able to record the date each completed response was submitted, we were able to compute response speed for each completed response by simply 220 counting the number of days between the return date and the request date.

\section{Respondent Satisfaction}

In addition to response rate and response quality measures, the issue of respondent satisfaction is also an important measure for evaluating effectiveness of survey research (Manfreda et al., 2002). As a 225 result of their research, Manfreda et al. (2002) argue that respondent satisfaction is particularly crucial to the success of web-based surveys. This involves gathering respondents' emotional status from survey participation immediately following the main survey task. As such, we asked respondents to rate their levels of satisfaction after partici- 230 pating in the main survey task using a 3-item scale. More specifically, respondents were asked to indicate their level of agreement regarding feelings of satisfaction, contentment, and pleasure after their participation in the survey task.

\section{Introductory Elements}

Survey introductory elements include the communication from researchers to respondents at the beginning introduction of a survey 
request (Brennan, Benson, \& Kearns, 2005). This study evaluates the use of an invitation from a known leader to request survey participation among adult community members. There does not appear 240 to be any research in the market research methodology literature that directly evaluates the effects of invitation from a person in a known leadership position.

For the purpose of this research, use of a known leader to request survey participation involves the use of the known leader's name and 245 position title in the beginning and end of the e-mail invitation. Furthermore, wording within the request was positioned as from the specific leader individual instead of a group of people or a board.

A second introductory element is the survey introductory length (Brennan, Benson, \& Kearns, 2005). This involves the length or num- 250 ber of words used to explain the survey request. For our purposes, we used a long survey invitation and a short survey invitation. The long version contained over twice as many words compared to the shorter survey introduction.

Lastly, this research takes an exploratory view of the use of a 255 hyperlink versus an attached form to determine participant preferences and effects on survey response factors. Each potential participant was given the opportunity to either 1) download the questionnaire, complete the answers and e-mail their responses or 2) click a hyperlink, respond to questions online and click submit.

\section{HYPOTHESES}

Although originating from sociology, marketing scholars have Q2 brought social exchange theory (Thibaut \& Kelly, 1959) into the marketing literature to help explain several aspects of business-to-business relationships (e.g., Dwyer, Schurr, \& Oh, 1987). The 265 underlying assumption of social exchange theory involves a moral obligation between the parties and the inherent reciprocity of relationship actions (Kingshott, 2006). Half of the potential respondents will receive the request for survey participation from the lead pastor of a church where they provided their contact information. 270 Many of these potential respondents are members of the church, former visitors, or regularly attend the church. Based on social exchange theory, potential respondents may feel a sense of obligation to contribute to the relationship with the church's lead pastor, 
particularly since it is likely that potential respondents attended at 275 least one church service in the past. This sense of obligation to pay back the church for the service or services attended may lead to a greater likelihood for potential respondents to participate when the lead pastor invites them to the survey. Furthermore, respondents may feel a sense of obligation to provide thoughtful and thorough 280 responses when a pastor specifically invites them to share their thoughts. Additionally, respondents may have stronger levels of satisfaction from survey participation if they feel that they have contributed to the relationship with the lead pastor. Hence, the following hypotheses are given:

Hypothesis 1a: Survey invitation from a known leader will increase response rate for online surveys.

Hypothesis $1 b$ : Survey invitation from a known leader will improve response quality for online surveys.

Hypothesis 1c: Survey invitation from a known leader will 290 increase respondent satisfaction for online surveys.

Brennan, Benson, \& Kearns (2005) tested for differences between using a short introduction versus a longer introduction to request survey participation. These scholars found that shorter introductions produced slightly higher levels of response rate, although the differ- 295 ence was not significant. Their research examined survey introductions in the context of telephone interviews where introductions were read to the potential respondents. This research is conducted via a text-based method (e-mail) and would therefore involve potential respondents reading the survey introduction instead of listening 300 to a verbal introduction. From the psychology literature, Hendrick \& Cunningham (2002) explain that there is strong support for the theory that describes information-processing tasks between reading and listening as nearly equivalent. Based on this theory, written long introductions are expected to impact survey response factors in the 305 same way as Brennan, Benson, \& Kearns' (2005) research using verbal long introductions.

From the communications literature, Wiksell (1946) emphasizes that verbal communication requires more attention and concentration on the part of the listener. Additionally, Wiksell (1946) argues 310 that listening may provide more possibilities for misunderstandings 
and lack of comprehension compared to reading. Therefore, it is possible that participants exposed to verbal-based survey introductions may not respond as acutely or intensely as respondents from a written survey introduction. Hence, the differences between short 315 and long introductions for surveys using written modes should be greater than those from verbal survey modes due to this increase in comprehension for written communication.

Based on the similar requirements for processing verbal and written information (Hendrick \& Cunningham, 2002) and the possi- 320 bilities for increased comprehension by the reader for written communication (Wiksell, 1946), the potential respondent reading the survey introduction may respond in the same direction as Brennan, Benson, \& Kearns' (2005) research; however, this response may occur with more intensity. Therefore, the following hypotheses 325 are given:

Hypothesis 2a: A shorter survey introduction will result in higher response rate for online surveys.

Hypothesis 2b: A shorter survey introduction will result in improved response quality for online surveys.

Hypothesis 2c: A shorter survey introduction will result in a higher level of respondent satisfaction for online surveys.

\section{METHOD AND ANALYSES}

A list of e-mail addresses from a local nonprofit organization (church) was obtained as the sample frame. These addresses include 335 current members, individuals who regularly attend the church, visitors of the church, and other individuals from the community who provided their e-mail address to the church. Efforts were made to reach each individual on the church's e-mail list no more or no less than one time to request survey participation.

A total of 1,863 e-mail messages were sent initially. Approximately $10 \%$ of the e-mail requests were returned undeliverable for various reasons. The e-mail message requesting survey participation included all survey introductory elements. While all outgoing correspondence originated from a single e-mail address, the subject line of the e-mail 345 and the introductory message varied. Half of the sent e-mail messages indicated that a known leader, the lead pastor, was requesting 
participation in a survey in the subject line. Furthermore, the introductory letter was written from the known leader with his personal invitation to participate and his signature. The other half of the e- 350 mail messages indicated that the organization in general was requesting participation in a survey. The introductory letter for this second half was written in more generic terms from the church. Furthermore, half of the potential respondents were given a short description of the survey's purpose while the other half were given a relatively long 355 description with about twice as many words used to describe the research. Lastly, the e-mail message provided a hyperlink to a Web site that contained the survey form and each e-mail message contained an attached Word document of the survey instrument, which respondents could download, save and resend via e-mail. In addition, 360 a mailing address and a fax number were also provided as options for returning completed responses. Therefore, respondents were given the option to use the attached form or to follow the provided link to the survey instrument.

Based on research by Faught, Whitten, \& Green (2004), surveys 365 conducted via e-mail receive significantly higher levels of response rate on Wednesday morning and Tuesday afternoon. Hence, all invitations were sent on Tuesday afternoon at approximately 2:00 pm.

\section{ANAL YSIS AND FINDINGS}

The effective sample frame of 1,696 resulted in a total of 280 useable responses representing a response rate of approximately $16.5 \%$. Respondent demographics reveal that the majority of respondents were married $(69 \%)$. The average age reported is 39 years old with a maximum age of 71 . Of those reporting gender, 29\% claimed male 375 and $71 \%$ claimed female. Average length of relationship with the church requesting participation was 5.9 years.

Response rate from the respondent group with an invitation to participate from a known leader $(n=141)$ is approximately equal to the response rate from the respondent group with a more generic 380 invitation $(n=139)$. This lack of difference suggests that an invitation to participate in a survey from a known leader does not appear to influence participation beyond that of a more generic invitation from an organization. Thus, H1a is not supported. 
Certain response quality measures appear to improve under con- 385 ditions of a leader invitation while other measures appear to remain unchanged. Response time and response speed were very similar between groups receiving a leader invitation versus those receiving a generic invitation. Stated minutes for response time among respondents receiving a leader invitation is 9.342 minutes while respondents 390 from a generic invitation gave an average response time of 9.337 minutes $(p=.995)$. Similarly, there are no significant differences $(p=.634)$ regarding response speed between leader and generic invitation respondents. For the generic invitation, the average number of item omissions is $5.35(n=139)$ while responses from the leader invi- 395 tation treatment group resulted in significantly lower $(p<.05)$ average item omission levels of $2.77(n=141)$. Other measures of response quality, such as completeness of answer, improved for the leader invitation group, although the difference was not significant $(p=.501)$. Therefore, our hypothesis that an invitation from a known 400 leader improves response quality (H1b) receives partial support.

Levels of respondent satisfaction measures were not significantly different between groups receiving a generic invitation versus those receiving an invitation from a known leader. Thus, our findings suggest that the use of a leader to request survey participation does not 405 positively or negatively impact respondents' feelings toward survey participation. Therefore, H1c is not supported.

To address $\mathrm{H} 2$, we evaluated differences in response levels using $t$-tests where groups were divided based on long or short survey invitations. Response level for the short invitation $(n=133)$ was similar 410 to the response received from the long invitation group $(n=147)$, resulting in no significant differences in response rate $(p=.36)$. Hence, there is no support for $\mathrm{H} 2 \mathrm{a}$.

Regarding response quality differences, a $t$-test reveals that only response speed revealed significant differences $(p<.05)$ between 415 groups receiving short (1.76 days) and long (3.04 days) invitations. Completeness of answer improved somewhat among responses from the shorter invitation treatment group; however, these differences were not significant. Other measures of response quality, including the number of item omissions and response time, did not significantly 420 differ based on length of survey invitation. Thus, findings provide only partial support for $\mathrm{H} 2 \mathrm{~b}$.

Levels of respondent satisfaction appear fairly consistent across groups. A $t$-test reveals no significant difference $(p=.46)$ between 
those receiving short- versus long-survey invitations. Therefore, 425 results provide no support for $\mathrm{H} 2 \mathrm{c}$.

We also took an exploratory examination of how factors including age, gender, and loyalty influence response quality. For age and loyalty, we split respondents based on the upper $40 \%$ and the lower $40 \%$ of the respondents for age and loyalty to the organization. While 430 there were not material differences based on length of relationship to the organization (loyalty), significant differences exist in measures of completeness of answer and item omissions by gender and age. Older female respondents appear to have higher levels of completeness of answer but are also more likely to skip close-ended questions 435 (item omissions) compared to younger male respondents.

Lastly, we explored the use of preferences for Internet-based surveying, e-mail attachment survey administration, or other methods for providing completed survey forms. Given the opportunity to respond via Internet, e-mail, mail, and fax resulted in approxi- 440 mately $70 \%$ of respondents choosing Internet as their method for providing response. Results suggest that the use of a hyperlink for Internet administration may produce higher levels of response.

\section{DISCUSSION}

The results of this study suggest that certain survey introductory 445 elements impact response quality but not other measures such as response rate and respondent satisfaction. An invitation from a known leader produced improved levels of response quality (item omissions) compared to a more generic invitation; however, this improvement was only present for one of the four dimensions of 450 response quality. Therefore, while the use of a known leader appears to have some value for encouraging higher response quality, researchers from the managerial and academic community should evaluate the cost of such an invitation when the appreciable benefits may only include a reduction in item omission rates.

Length of survey invitation appears to impact response quality with shorter invitations resulting in quicker responses from participants. While respondent satisfaction and response rate did not appear to improve from the use of shorter invitations, the improvement to this single dimension within response quality may justify the use of shorter 460 invitations for managerial and academic research studies. 
Lastly, the use of a hyperlink with an Internet-based survey tool appears to dominate other methods as the preferred method for survey participation. Hence, researchers may consider the benefits improved measures of response quality and quicker response speed 465 when considering the possibility of using short introductory descriptions from a known leader using an Internet-based survey tool.

\section{LIMITATIONS AND DIRECTIONS FOR FUTURE RESEARCH}

The sample frame for this research involved individuals who provided 470 their name and e-mail address to a church. Clearly, there are groups of consumers who are not represented from this sample frame, but the variety of consumers represented by this sample is adequate to begin exploration of these issues. Future studies should seek to improve the generalizability of these findings by exploring different organizations.

In addition, this study did not address the impact of gender, age, or loyalty to the organization in a comprehensive way. Clearly a larger number of females responded to the request. Due to that nature of e-mail and family affiliation with the organization, it was impossible to determine at the start which gender would be receiving the request. 480 Furthermore, a more detailed analysis by age and loyalty is warranted to help discover the most response quality of various subgroups. Perhaps future studies utilizing a business organization could control for these factors.

Furthermore, future studies should include several other introduc- 485 tory elements to evaluate their importance in requesting and receiving quality survey response. Also, academics and practitioners alike could benefit from further knowledge of the possible effects of design and cosmetic factors surrounding survey instrument appearance.

\section{CONCLUSION}

This research adds to the growing body of knowledge regarding online methods for data collection. While there are limitations to this research, these findings can assist the academic and managerial communities to design survey introductions that result in higher response 
rates, improved response quality, and higher levels of respondent 495 satisfaction.

\section{REFERENCES}

Andersen, P. A. \& Blackburn, T. R. (2004). An experimental study of language intensity and response rate in e mail surveys. Communication Reports, Vol. 17, 500 No. 2, pp. 73-82.

Baruch, Y. (1999). Response rate in academic studies - A comparative analysis. Human Relations, Vol. 52, No. 4, pp. 421-38.

Birnholtz, J. P., Horn, D. B., Finholt, T. A., \& Bae, S. J. (2004). The effects of cash, electronic, and paper gift certificates as respondent incentives for a web-based sur- 505 vey of technologically sophisticated respondents. Conference Papers-American Association for Public Opinion Research, Vol. 22, No. 3, pp. 355-62.

Brennan, M., Benson, S., \& Kearns, Z. (2005). The effect of introductions on telephone survey participation rates. International Journal of Market Research, Vol. 47, No. 1, pp. 65-74.

Bush, A. J. (1984). Assessing response quality. Psychology \& Marketing, Vol. 1, No. 3/4, pp. 57-71.

Bush, A. J. \& Hair, J. F. (1985). An assessment of the mall intercept as a data collection method. Journal of Marketing Research, Vol. 22, May, pp. 158-67.

Cobanoglu, C., Warde, B., \& Moreo, P. J. (2001). A comparison of mail, fax and 515 web-based survey methods. International Journal of Market Research, Vol. 43, No. 4, pp. 441-52.

Cycyota, C. S. \& Harrison, D. A. (2006). What (not) to expect when surveying executives: A meta-analysis of top manager response rates and techniques over time. Organizational Research Methods, Vol. 9, No. 2, pp. 133-60.

Dillman, D. A. (2000). Mail and Internet surveys: The tailored design method, Wiley, New York.

Dwyer, F. R., Schurr, P. H., \& Oh, S. 1987. Developing buyer-seller relationships. Journal of Marketing, Vol. 51, No. 2, pp. 11-27.

Faught, K. S., Whitten, D., \& Green, Jr., K. W. (2004). Doing survey research on the 525 Internet: Yes, timing does matter. Journal of Computer Information System, Vol. 44, No. 3, pp. 26-34.

Grant, D. B., Teller, C., \& Teller, W. (2005). Hidden opportunities and benefits in using web-based business-to-business surveys. International Journal of Market Research, Vol. 47, No. 6, pp. 641-66.

Griffis, S. E., Goldsby, T. J., \& Cooper, M. (2003). Web-based and mail surveys: A comparison of response, data and cost. Journal of Business Logistics, Vol. 24, No. 2, pp. 237-58.

Hanna, R. C., Weinberg, B., Dant, R. P., \& Berger, P. D. (2005). Do Internet-based surveys increase personal self-disclosure. Journal of Database Marketing \& Cus- 535 tomer Strategy Management, Vol. 12, No. 4, pp. 342-56. 
Hendrick, W. B. \& Cunningham, J. W. (2002). Investigating the effects of wide reading on listening comprehension of written language. Reading Psychology, Vol. 23, No. 2, pp. 107-26.

Q4 Ilieva, J., Baron, S., \& Healey, N. M. (2002). Online surveys in marketing 540 research: Pros and cons. International Journal of Market Research, Vol. 44, No. 3, pp. 361-78.

Kent, R. \& Brandal, H. (2003). Improving email response in a permission marketing context. International Journal of Market Research, Vol. 45, No. 4, pp. 489-503.

Kingshott, R. P. J. (2006). The impact of psychological contracts upon trust and 545 commitment within supplier-buyer relationships: A social exchange view. Industrial Marketing Management, Vol. 35, No. 6, pp. 724-39.

Manfreda, K. L., Batagelj, Z., \& Vehovar, V. (2002). Design of web survey questionnaires: Three basic experiments. Journal of Computer-Mediated Communication,

Q3 Vol. 7, No. 3, pp. 0-0.

McConkey, C. W., Stevens, R. E., \& Loudon, D. L. (2003). Surveying the service sector: A pilot study of the effectiveness of mail vs. internet approaches. Service Marketing Quarterly, Vol. 25, No. 1, pp. 75-84.

McDaniel, S. W. \& Rao, C. P. (1980). The effect of monetary inducement on mailed questionnaire response quality. Journal of Marketing Research, Vol. 17, No. 2, pp. 555 265-68.

McNaughton, R. B. 1999. Disk by mail for industrial survey research. Industrial Marketing Management, Vol. 28, No. 3, pp. 293-304.

O'Cass, A. \& Fenech, T. (2003). Web retailing adoption: Exploring the nature of Internet users web retailing behavior. Journal of Retailing \& Consumer Services, 560 Vol. 10, No. 2, pp. 81-94.

Roster, C. A., Rogers, R. D., \& Albaum, G. (2004). A comparison of response characteristics from web and telephone surveys. International Journal of Market Research, Vol. 46, No. 3, pp. 359-73.

Roster, C. A., Rogers, R. D., Hozier Jr., G. C., Baker, K. G., \& Albaum, G. (2007). 565 Management of marketing research projects: Does delivery method matter anymore in survey research? Journal of Marketing Theory and Practice, Vol. 15, No. 2, pp. 127-44.

Roy, A. \& Berger, P. (2005). E-mail and mixed mode database surveys revisited: Exploratory analyses of factors affecting response rates. Journal of Database Mar- 570 keting \& Customer Strategy Management, Vol. 12, No. 2, pp. 153-71.

Seiders, K., Voss, G. B., Grewal, D., \& Godfrey, A. L. (2005). Do satisfied customers buy more? Examining moderating influences in a retailing context. Journal of Marketing, Vol. 69, No. 4, pp. 26-43.

Shaw, M., Bednall, D., \& Hall, J. (2002). A proposal for a comprehensive response- 575 rate measure (CRRM) for survey research. Journal of Marketing Management, Vol. 18, No. 5/6, pp. 533-554.

Singer, E. 1978. The effect of informed consent procedures on respondents' reactions to surveys. Journal of Consumer Research, Vol. 5, No. 1, pp. 49-57.

Singer, E. \& Frankel, M. R. (1982). Informed consent procedures in telephone inter- 580 views. American Sociological Review, Vol. 47, No. 3, pp. 416-26. 
Smith, D. M., Schwarz, N., Roberts, T. R., \& Ubel, P. A. (2006). Why are you calling me? How study introductions change response patterns. Quarterly of Life Research, Vol. 15, No. 4, pp. 621-30.

Q5 Thibaut, J. W. \& Kelley, H. H. (1959). The social psychology of groups, Wiley, 585 New York.

Tse, A. C. B. (1998). Comparing the response rate, response speed and response quality of two methods of sending questionnaires: E-mail vs. mail. Journal of the Market Research Society, Vol. 40, No. 4, pp. 353-61.

Weible, R. \& Wallace, J. (1998). Cyber research: The impact of the Internet on data 590 collection. Marketing Research, Vol. 10, No. 3, pp. 18-31.

Wiksell, W. (1946). The problem of listening. Quarterly Journal of Speech, Vol. 32, No. 4, p. 505.

Wright, D. L., Aquilino, W. S., \& Supple, A. J. (1998). A comparison of computerassisted paper-and-pencil self-administered questionnaires in a survey on smoking, 595 alcohol, and drug use. Public Opinion Quarterly, Vol. 62, No. 3, pp. 331-53.

Zviran, M., Glezer, C., \& Avni, I. (2006). User satisfaction from commercial websites: The effect of design and use. Information \& Management, Vol. 43, No. 2, pp. 157-78.

SUBMITTED: December 2007600

REVISION: January 2008

ACCEPTED: January 2008 